\title{
Processo grupal: reflexões de uma equipe de enfermagem*
}

\author{
GROUP PROCESS: REFLECTIONS OF A NURSING TEAM
}

\author{
PROCESO GRUPAL: REFLEXIONES DE UN EQUIPO DE ENFERMERÍA
}

\author{
Adriana Serdotte Freitas Cardoso ${ }^{1}$, Clarice Maria Dall'Agnol ${ }^{2}$
}

\section{RESUMO}

Estudo qualitativo, exploratório-descritivo com o objetivo de analisar o processo grupal de uma equipe de enfermagem do Hospital de Clínicas de Porto Alegre (HCPA), à luz da Teoria de Grupo Operativo de Pichon-Rivière. A coleta de dados ocorreu em 2008, por meio de questionário semiestruturado e grupo focal. Concepção de trabalho em grupo é uma das quatro categorias resultantes do estudo, sendo objeto de abordagem neste artigo. Depreendeu-se que o conhecimento sobre processo grupal necessita ser compartiIhado, divulgado e discutido desde a formação acadêmica, no curso de graduação em enfermagem, e desenvolvido ao longo de toda a carreira profissional. À medida que se conhece e consegue identificar os principais indicadores presentes no processo grupal, a equipe pode conduzir-se operativamente, considerando não apenas resultados, mas principalmente o caminho percorrido até o alcance da tarefa, visando à aprendizagem grupal.

\section{DESCRITORES}

Equipe de enfermagem

Processos grupais

Grupos focais

Comunicação

Relações interprofissionais

\begin{abstract}
The objective of this qualitative, exploratory-descriptive study was to analyze the group process of a nursing team at Hospital de Clínicas de Porto Alegre (HCPA), under the light of Pichon-Rivière's Operative Group Theory. Data collection took place in 2008, using a semi-structured questionnaire and focal group. The group work concept is one of the four categories that resulted from the study, and is the object of approach in the present article. It was found that the knowledge about the group process must be shared, disseminated and discussed since the undergraduate studies and developed across the professional career. As the team learns and is able to identify the main indicators of the group process, it becomes possible to improve operatively, considering not only the outcomes but mainly the course covered until achieving the goal, aiming at group learning.
\end{abstract}

\author{
DESCRIPTORS \\ Nursing, team \\ Group processes \\ Focus groups \\ Communication \\ Interprofessional relations
}

\section{RESUMEN}

Estudio cualitativo, exploratorio, descriptivo, que objetivó analizar el proceso grupal de un equipo de enfermería del Hospital de Clínicas de Porto Alegre (HCPA), según la Teoría de Grupo Operativo de PichonRivière. La recolección de datos aconteció en 2008, mediante cuestionario semiestructurado y grupo focal. Concepción de trabajo en grupo es una de las cuatro categorías resultantes del estudio, siendo objeto de abordaje en este artículo. Se desprendió que el conocimiento sobre proceso grupal necesita ser compartido, divulgado y discutido desde la formación académica, en el curso de graduación en enfermería, y desarrollado a lo largo de toda la carrera profesional. A medida que se conoce y consigue identificar los principales indicadores presentes en el proceso grupal, el equipo puede conducirse operativamente, considerando no sólo resultados, sino principalmente el camino recorrido hasta la conclusión de la tarea, apuntando al aprendizaje grupal.

\section{DESCRIPTORES}

Grupo de enfermería

Procesos de grupo

Grupos focales

Comunicación

Relaciones interprofesionales

\footnotetext{
* Extraído da dissertação "Análise do processo grupal de uma equipe de enfermagem", Escola de Enfermagem da Universidade Federal do Rio Grande do Sul, 2009. ${ }^{1}$ Mestre em Enfermagem. Enfermeira Assistencial do Hospital de Clínicas de Porto Alegre. Membro do Núcleo de Estudos de Gestão em Enfermagem (NEGE). Porto Alegre, RS, Brasil. aserdotte@hcpa.ufrgs.br ${ }^{2}$ Doutora em Enfermagem. Professora da Escola de Enfermagem da Universidade Federal do Rio Grande do Sul. Coordenadora do Núcleo de Estudos de Gestão em Enfermagem (NEGE). Porto Alegre, RS, Brasil. clarice@adufrgs.ufrgs.br 


\section{INTRODUÇÃO}

Coordenar um grupo de pessoas é algo, por vezes, bastante difícil, sendo inevitável deparar-se com as marcas da diversidade pois, além de motivações diversas, diferentes pensamentos, formas de agir e conceber ideias circulam num grupo de trabalho. Em meio a tantas peculiaridades, no entanto, é preciso convergir esforços para alcançar objetivos e metas que sejam comuns a todos e que se traduzam na finalidade do próprio grupo. Nesse contexto, o enfermeiro destaca-se como um profissional que tem a responsabilidade de coordenar equipes, geralmente constituídas de auxiliares e técnicos de enfermagem, além de outros enfermeiros.

Cabe ressaltar que, embora o ser humano faça parte de grupos ao longo de toda a sua vida (família, escola, igreja, clube, etc.), nem sempre esse processo de inserção é percebido claramente. No entanto, desde o nascimento do indivíduo, é exigida uma disposição para a sociabilidade, para tornar-se membro de uma sociedade, já que não possui condições físicas suficientes que o permitam sobreviver isoladamente ${ }^{(1)}$. Deste processo contínuo de inserção em grupos, depreende-se a natureza gregária do ser humano, que busca constantemente preservar sua identidade, no espaço micro e macro social. As muitas relações vivenciadas, de alguma forma causaram e/ou causam impacto na individualidade de cada um. É necessário considerar que, num grupo, várias redes se cruzam, cada qual portando seus valores, crenças, medos, afinidades e mecanismos de defesa. O patrimônio acumulado de cada indivíduo, repleto dessa herança coletiva, traduz as nuanças do processo de comunicação do grupo do qual ele faz parte, que é peculiar e único. Outras pessoas, com bagagens diferentes, proporcionarão outras combinações ${ }^{(2)}$.

A dimensão coletiva do trabalho do enfermeiro requer um conhecimento acerca da dinâmica grupal, que não se restringe à simples utilização de técnicas, mas sim da compreensão dos movimentos grupais em razão de sua complexidade. Por não ter uma formação específica para isso, por ocasião da formação acadêmica na graduação, o enfermeiro depara-se com grandes dificuldades ao enfrentar o mercado de trabalho e ao se ver frente a obstáculos na liderança, na comunicação e no relacionamento interpessoal, pois coordenar grupos não se constitui tarefa simples ${ }^{(3)}$.

O desenvolvimento das habilidades para a coordenação de grupos, quando ancorado em um referencial teórico-prático - neste caso, o de Grupo Operativo -, possibilita sustentação à compreensão dos diversos processos que ocorrem no interior do grupo e dos recursos que o coordenador precisa para o seu manejo. A compreensão dos movimentos grupais implica em uma habilidade fundamental, tanto para melhorar a eficácia das intervenções do coordenador, quanto para investigar e estimular os potenciais do próprio grupo.

Assim, através da criação de um espaço de interlocução, tendo como princípio a participação, em diversas formas e graus de intensidade, de todos os atores envolvidos nos questionamentos propostos, o objetivo geral deste estudo consistiu em analisar o processo grupal de uma equipe de enfermagem, sendo que os resultados apresentados neste artigo derivam de um dos desdobramentos que foi conhecer a concepção da equipe de enfermagem sobre trabalho em grupo. Portanto, almeja-se contribuir para o desenvolvimento de um processo reflexivo que possa fornecer subsídios para intervenções e reorientações das práticas da equipe, favorecendo e desencadeando possibilidades de investigação e compreensão do processo grupal na equipe de enfermagem.

\section{REVISÃO DE LITERATURA}

No intuito de compreender as relações existentes na equipe de enfermagem, é preciso estar ancorado em referenciais teóricos que possam subsidiar tal compreensão. 0 referencial de grupo operativo proporciona a sustentação para a escolha de técnicas adequadas e para a intervenção grupal. Intervenção que, pretende-se, aconteça em favor de uma perspectiva transformadora na qual as pessoas que participam de um processo grupal sejam vistas como sujeitos capazes de uma construção conjunta, tendo claras as possibilidades e os limites.

No presente estudo, adota-se o entendimento de trabalho em equipe como um processo de inter-relação, analisando as relações entre os trabalhadores enquanto processos grupais. A partir da compreensão dos processos grupais presentes nas relações de uma equipe, pode-se construí-la, utilizando-se de críticas e reflexões distintas das até então realizadas. Ao encontro dessa proposta, o referencial pichoniano de grupo operativo tem a intenção de auxiliar as equipes ao longo do processo de compreensão e construção de sua práxis, possibilitando ações transformadoras que recriem o seu próprio trabalho.

Compreender a dinâmica que percorre a construção-desconstrução-reconstrução de uma equipe de saúde constitui um grande desafio. Na construção da grupalidade, perpassam as noções de recomposição de saberes e da equipe como totalidade, embora se entenda que essa totalidade não existe, nem a uniformidade de ideias e de visão de mundo. No imaginário grupal, a ilusão de equipe perfeita permanece mais no plano da idealização do que propriamente da realidade, sendo necessário quebrar 
o mito da perfeição e aprender a lidar com as imperfeições ${ }^{(4-5)}$. Isso desencadeia um processo criativo a partir dos recursos que já se possui, o que caracteriza um contínuo processo em espiral(6).

A técnica do grupo operativo caracteriza-se por estar centrado na tarefa, em suas dimensões explícita e implícita. De uma forma explícita, a tarefa pode ser a aprendizagem, o diagnóstico de uma organização profissional, a criação publicitária, etc. Sob essa tarefa, subjaz outra, que aponta a ruptura de pautas estereotipadas que dificultam a aprendizagem e a comunicação, significando um obstáculo frente a toda situação de progresso ou mudança. Assim, a tarefa implícita consiste na elaboração de duas ansiedades básicas entendidas como o medo da perda da estabilidade conquistada pela situação anterior e o medo do ataque na nova situação. Essas duas ansiedades, coexistentes e cooperantes, configuram a situação básica de resistência à mudança que, no grupo operativo, deve ser superada num acontecer grupal no qual se cumprem os três momentos dialéticos de tese, antítese e síntese, por meio de um processo de esclarecimento que vai do explícito ao implícito. A alusão a um modo operativo relaciona-se a operar no sentido de criar condições para que os integrantes promovam uma modificação criativa e uma adaptação ativa à realidade, o que significa compreender o grupo como instrumento a serviço da aprendizagem ${ }^{(6)}$.

Segundo essa perspectiva, aprender em grupo significa preocupar-se, não somente com o produto da aprendizagem, mas também com o processo que possibilita a mudança dos sujeitos para a vida. Deste modo, o trabalho em grupo operativo tem a intenção de levar a pessoa a aprender a pensar, ou melhor, reaprender a pensar, transformando uma modalidade de pensamento dilemática em outra, dialética. O pensamento dilemático desencadeia um estancamento da possibilidade de aprendizagem, criatividade e transformação da realidade. Essa forma de pensar estabelece uma leitura distorcida da realidade ao fragmentar o objeto de conhecimento, dissociando-o de outros objetos e do contexto em que está inserido, produzindo também uma fragmentação do vínculo e do eu. Em contrapartida, o pensamento dialético busca integrar o objeto, compreendendo-o em constante movimento, articulado a outros objetos e ao contexto, em uma situação histórica concreta( ${ }^{(6)}$.

Reaprender a pensar, a partir do pensamento dialético, está relacionado à busca de uma visão mais reflexiva da vida cotidiana. Os fatos e fenômenos do cotidiano apresentam-se, na maioria das vezes, como algo não-questionável ou não-problematizado, como se já constituíssem o real por excelência. Desta forma, o cotidiano acaba por tornar-se encoberto, distorcido: esse encobrimento e distorção acontecem por meio de um mecanismo peculiar, característico da ideologia dominante, que naturaliza o social, universaliza o particular e torna atemporal o que é histórico. Através desse processo mistificador, a vida cotidiana constitui uma ordem natural, universal, eterna e não-modificável ${ }^{(7)}$. Sendo assim, a técnica operativa do grupo, sejam quais forem os objetivos propostos no grupo (aprendizagem, diagnóstico institucional, planejamento, etc.), "tem como finalidade que seus integrantes aprendam a pensar numa coparticipação do objeto do conhecimento, entendendo-se que pensamento e conhecimento não são fatos individuais, mas produções sociais"(6).

O grupo operativo fundamenta-se na ideia de que o processo envolvido para alcançar a tarefa resulte em aprendizagem, ou seja, ler criticamente a realidade. Aprender significa um processo que possibilita mudança dos sujeitos envolvidos na tarefa, para aumentar a capacidade individual e grupal de compreensão da realidade e construção de meios para transformá-la. Desta forma, o grupo operativo não está centrado nem nas pessoas nem no grupo, mas sim no processo de inserção do sujeito no grupo ${ }^{(6)}$.

Em razão do exposto, pontua-se a revitalização do referencial pichoniano nas questões do trabalho em saúde, possibilitando um constante repensar e, fundamentalmente, um refazer a prática, como sujeitos críticos e criativos que podem, coletivamente, transformar o cotidiano. Considerando que pensar em sujeitos críticos e criativos é uma das questões primordiais que vêm sendo enfocadas atualmente na Enfermagem, tendo em vista as novas diretrizes curriculares propostas ${ }^{(8)}$, essa abordagem pode ser mais uma possibilidade para a busca de transformações na prática do gerenciamento em Enfermagem, objetivando a horizontalização das relações.

\section{MÉTODO}

Este estudo, em sua abrangência, caracteriza-se como qualitativo, exploratório-descritivo, alicerçado no método de pesquisa-ação( ${ }^{(9)}$, tomando-se como campo de pesquisa uma unidade de internação de pacientes adultos do Hospital de Clínicas de Porto Alegre (HCPA). O HCPA é integrante da rede de hospitais universitários do Ministério da Educação e está vinculado academicamente à Universidade Federal do Rio Grande do Sul (UFRGS). Atualmente, a estrutura física do HCPA comporta 750 leitos, disponibilizando atendimento em 62 especialidades para usuários, em sua maioria do Sistema Único de Saúde, provenientes de Porto Alegre, região metropolitana e interior do estado do Rio Grande do Sul(10).

A unidade de internação onde ocorreu a coleta de dados possui capacidade para 45 leitos, distribuídos em 15 enfermarias, cada uma com 3 leitos, caracterizando-se pela internação de pacientes adultos. A equipe de enfermagem compõe-se de 45 profissionais. Dentre eles, 36 são auxiliares de enfermagem e 9 são enfermeiros, alocados nos turnos manhã, tarde, noite, intermediário (17h às 23h15) e sexto turno (plantões diurnos de $12 \mathrm{~h}$ abrangendo apenas finais de semana e feriados).

Neste estudo, houve duas etapas de coleta de dados. A primeira ocorreu durante o mês de junho de 2008 e constituiu na aplicação de um questionário contendo questões semiestruturadas de livre resposta com o objetivo de son- 
dar percepções gerais dos participantes quanto ao processo grupal da equipe de enfermagem. Os respondentes preencheram o instrumento, individualmente, durante o seu turno de trabalho e depositaram o questionário em uma caixa coletora disponível na unidade. Adotou-se como critérios de inclusão ser integrante da equipe de enfermagem, voluntariedade e interesse em discutir a temática e como critérios de exclusão afastamentos diversos, como aqueles motivados por férias e licenças, tendo-se assegurado a livre participação. Assim, do total de 45 trabalhadores de enfermagem, contou-se com 33 respondentes, excluindo-se 12 trabalhadores que estavam em férias e/ ou licenças diversas. A segunda etapa ocorreu no período de agosto a outubro de 2008, mediante grupo focal, totalizando 5 encontros, com duração média de uma hora e participação de sete sujeitos. Adotou-se como critério de inclusão o interesse pela temática e a disponibilidade para participar dos encontros.

Devido a um momento vivido pela unidade, o grupo de auxiliares mobilizava algumas ansiedades quando do momento das inscrições, ocasionando apenas duas inscrições por parte dessa categoria profissional. Entretanto, questões logísticas demandaram alteração na composição do grupo. Cita-se a dificuldade de cobertura dos auxiliares de enfermagem que necessitariam estar ausentes durante o seu turno de trabalho para poderem participar do grupo focal, bem como o período da coleta, que abrangia férias e licenças e a necessidade de um cronograma de pesquisa já estabelecido. Desse modo, o grupo de pesquisa constitui-se apenas com as enfermeiras da unidade.

As sessões foram gravadas em áudio e transcritas literalmente pela própria pesquisadora. A Equipe de coordenação constituiu-se da moderadora dos debates (mestranda) e da observadora-participante. Esta última, além de integrar o mesmo núcleo de pesquisa (NEGE), tinha experiência prévia na execução da técnica de grupos focais.

As informações obtidas por meio dos questionários foram analisadas da seguinte forma: para os resultados das perguntas fechadas, utilizou-se a estatística descritiva; as informações foram dispostas em tabelas de modo a se poder verificar a frequência de cada resposta, expressa em valores absolutos e percentuais. Já os resultados das questões semiestruturadas de livre resposta foram classificados por similaridade de conteúdo, agrupando-os em pré-categorias, utilizando-se como referencial a análise temática ${ }^{(11)}$. Os resultados obtidos a partir do questionário semiestruturado subsidiaram a construção do guia de temas norteadores para a condução das sessões do grupo focal. Da mesma forma, o manancial de informações geradas no grupo focal também foi submetido à análise temática.

Com relação aos aspectos éticos, atentou-se para as recomendações contidas na Resolução 196/96 do ConseIho Nacional de Saúde ${ }^{(12)}$. O projeto somente teve início após homologação na Comissão Científica e Comissão de Ética em Pesquisa do Hospital de Cínicas de Porto Ale- gre, (protocolo número 08-116). Na primeira etapa da coleta de dados, forneceu-se a cada participante uma Folha Explicativa acompanhando o Questionário, em que constavam informações consubstanciadas do projeto. Os Questionários foram recolhidos em caixa coletora, sem identificação dos respondentes. A realização do grupo focal foi precedida da assinatura, em duas vias, do Termo de Consentimento Livre e Esclarecido (TCLE), ficando uma via com o pesquisador e outra com cada sujeito participante.

\section{RESULTADOS E DISCUSSÃO}

O resultado das questões fechadas do questionário subsidiou uma breve caracterização dos 33 participantes enquanto trabalhadores de enfermagem que atuam na unidade, campo de pesquisa. Verificou-se o predomínio do sexo feminino (68\%) e da faixa etária situada entre 41 e 50 anos de idade (34\%). Quanto ao tempo de serviço, observou-se que a maioria dos respondentes (43\%) exerce profissionalmente a enfermagem por um período superior a 15 anos, sendo que nenhum dos sujeitos afirmou exercer a enfermagem por um período inferior a 5 anos. Verificou-se também que a maioria dos sujeitos (60\%) vem mantendo vínculo no HCPA há mais de 5 anos assim como $54 \%$ deles integram a equipe de enfermagem da unidade campo de estudo também há mais de 5 anos. Os resultados obtidos por meio das questões semiestruturadas de livre resposta do questionário forneceram pistas acerca da percepção dos membros da equipe sobre o processo grupal do qual ela faz parte, tendo sido agrupados em quatro eixos temáticos: concepção de trabalho em grupo, aspectos dinamizadores/obstaculizadores do processo grupal, nós críticos do processo grupal e estratégias para a construção do trabalho em grupo. Estes eixos temáticos, abstraídos da análise dos questionários, constituíram os disparadores das discussões no grupo focal.

Os resultados do grupo focal foram agrupados em quatro categorias temáticas: concepção de trabalho em grupo; a comunicação como aspecto central que dinamiza/obstaculiza o processo grupal; o distanciamento entre as categorias profissionais como principal nó crítico do processo grupal e estratégias para a construção do trabaIho em grupo. Neste artigo, são analisados e discutidos os dados referentes à categoria concepção de trabalho em grupo. As falas ilustrativas dos debates no grupo focal são identificadas como P1 (Participante 1), P2 (Participante 2) e assim sucessivamente.

\section{Concepção de trabalho em grupo}

A partir da pergunta norteadora o que você entende por trabalho em grupo? Desencadeou-se o debate e os participantes do grupo focal, após alguns instantes de reflexão, sugeriram que trabalho em grupo é possuir um objetivo comum:

[...] para mim é isso de objetivo comum, o trabalho com diversas pessoas, mas sempre com um objetivo comum (P1). 
[...] trabalhamos com a finalidade do paciente (P7).

O conceito de grupo fornece a noção de um conjunto de pessoas com um objetivo comum, que opera e se estrutura à medida que se relaciona(6). Aproximando-se do referencial pichoniano, o sentido de objetivo comum relaciona-se com a concepção de tarefa, que consiste na abordagem e elaboração, pelo próprio grupo, das suas ansiedades existentes.

Objetivando enriquecer a discussão, outras enfermeiras colocaram que a concepção de trabalho em grupo perpassa a noção de cooperação e está vinculada à articulação das ações:

Eu acho que para mim trabalho em grupo é uma questão de cooperação (P3).

Eu acho que vai além da cooperação [...] tu consegue cooperar quando tu consegue pensar ou seguir a mesma linha do teu colega (P1).

No referencial pichoniano, a cooperação é concebida como um dos seis indicadores para avaliar o processo grupal. A cooperação se estabelece mediante uma elaboração conjunta dos obstáculos, o que contribui para o alcance da tarefa grupal ${ }^{(6)}$. Nesse processo, faz-se necessária a articulação entre as necessidades individuais e grupais, o que resulta, muitas vezes, no surgimento da competição, cujo objetivo é impedir a atuação do outro e, ao invés de complementá-lo, tenta-se ocupar seu lugar. Relacionado a isso, emergiu na discussão que trabalhar em grupo é conseguir lidar com situações de competição. Fato que foi percebido e sinalizado por uma das enfermeiras:

[...] parece que alguém, não sei, às vezes eu percebo um clima de competição [...] pedir uma ajuda, falar com a chefia [...] eles ficam ah, é o mais queridinho da chefe, ás vezes rola isso $(\mathrm{P} 1)$.

O clima de competição a que se refere a fala, evidenciado por sutis disputas entre os membros da equipe no cotidiano do trabalho, pode ser consequência de práticas reiterativas como herança e tributo de modelos neoliberais. Refletindo sobre o ambiente competitivo no qual a enfermagem está inserida, a competição pode estar diretamente relacionada à sobrecarga de trabalho, à falta de melhores salários e à grande demanda de serviços para um contingente insuficiente de profissionais ${ }^{(13)}$. Isto pode ser explicado porque, inseridas no atual modelo capitalista de produção, as pessoas empenham-se em produzir mais em menos tempo, focando-se no aspecto técnico e na busca constante por produtividade.

No grupo, as pessoas estão permanentemente interatuando(14-16), sendo que tanto os objetivos individuais quanto os grupais vão se modificando com o decorrer do tempo e, por isso, os grupos precisam estar constantemente conversando sobre eles. Sobre essa questão, uma enfermeira afirmou:

[...] o trabalho tem um sentido diferente para cada pessoa, uns estão aqui porque gostam, outros porque acham um bom trabalho, um emprego, outros porque é uma fonte de renda (P1).

Nesse sentido, de acordo com os sujeitos da pesquisa, a concepção de trabalho em grupo também relaciona-se com a forma como este trabalho é percebido pelos seus integrantes.

Entende-se que o sentido do trabalho percorre o processo do início à conclusão ${ }^{(17)}$. Quando se perde a finalidade do trabalho, tem-se como consequência a alienação. Nessa situação, o trabalhador passa a desempenhar sua função sem conseguir compreender qual a importância das suas atividades e onde elas se encaixam no processo de trabalho como um todo.

Assim, pondera-se que o sujeito passa da grupalidade à serialidade comprometendo os indicadores de afiliação e pertença. Nas inter-relações dialéticas que ocorrem no interior de um grupo, a grupalidade é percebida como um movimento horizontal, em que o indivíduo passa a tomar parte em uma história construída coletivamente pelo grupo. Já a serialidade é entendida como um movimento vertical, que abrange a história pessoal do indivíduo, com suas representações internas, transferências e projeções ${ }^{(18)}$.

A pertença caracteriza-se pelo sentimento de estar integrado a um grupo, de identificar-se com ele, de incluir-se e incluir os demais em seu mundo interno. É através da pertença que se estabelece tanto a identidade do grupo quanto a do indivíduo ${ }^{(6)}$.

Logo em seguida, motivadas pelo debate que prossegue, outra enfermeira complementou, sinalizando outro ponto importante para o trabalho grupal:

[...] e tu não conhecendo a pessoa, tu nem sabe que ela tá passando por um problema (P3).

De fato, o conhecimento e a aproximação entre os membros do grupo é um diferencial na análise do processo grupal, sendo que na óptica dos grupos salientam-se o senso de inclusão, valorização e identificação entre os seus membros ${ }^{(19)}$. Mediante uma metáfora, compara-se a constituição de um grupo com uma galeria de espelhos, onde cada integrante pode refletir e ser refletido nos e pelos outros, de modo a oportunizar a discriminação, afirmação e consolidação de suas próprias identidades. Estabelece-se, então, uma relação em que cada indivíduo sente-se acolhido, e onde a situação do outro reflete a sua própria situação pessoal. A partir daí, a base de sustentação e fortalecimento das relações é constituída e as vivências transformam-se em aprendizado(20-21).

Quando uma pessoa consegue compreender a si mesma e sabe que pode ser afetada pelo comportamento do outro, passará a ter consciência de que o seu comportamento também poderá afetar o outro ${ }^{(16)}$. Esse fenômeno de aproximação e/ou distanciamento entre alguns integrantes do grupo é conhecido por tele ou telê, que consiste na capacidade ou disposição que cada um de nós tem 
para trabalhar com outras pessoas ${ }^{(6)}$. A tele negativa é a medida das dificuldades que cada um tem no trabalhar com o outro, da rejeição, a tele positiva compreende a possibilidade que o indivíduo tem de trabalhar com o outro, de aceitação do outro ${ }^{(6)}$. As teles positiva e negativa darão os fatores afetivos e o clima afetivo, favorecendo a tarefa ou tornando-se um obstáculo a ela. Dessa forma, o campo de trabalho em direção à tarefa será tanto mais favorável quanto mais se manifestar a tele positiva(6).

A maneira como se dão as relações com os colegas de equipe podem influenciar no resultado do trabalho. Da incapacidade de elaborar essas diferenças acabam surgindo os conflitos. Entretanto, os conflitos fazem parte da vida e do processo gerencial. No momento em que pessoas diferentes aprendem a lidar com as suas diferenças, o conflito torna-se construtivo. Sendo assim, o conflito não é considerado como algo negativo, mas sim como uma possibilidade de construção e crescimento coletivo mediante um processo dialético.

\section{CONCLUSÃO}

Uma importante questão diz respeito ao cotidiano de trabalho da equipe, permeado de relações conflituosas que, por vezes, tornam o trabalho em grupo e, consequentemente, o alcance de objetivos comuns, um emaranhado de percepções, onde as marcas da diversidade dão o tom.

A concepção de trabalho em grupo está relacionada ao alcance de objetivos em comum, perpassando as noções de cooperação e capacidade de articulação das ações. Para os membros do grupo focal, a não-articulação de objetivos individuais e grupais, muitas vezes, pode levar ao surgimento da competição entre os integrantes da equipe. Nas discussões, fez-se alusão à dificuldade de se estabelecer um eixo participativo comum, no que tange a conseguir articular-se cooperativamente para a realização da tarefa, evitando a justaposição e fragmentação das ações.

O desafio de conseguir articular objetivos grupais e individuais, segundo a percepção das participantes do grupo focal, está interligado ao sentido que o trabalho representa para as pessoas. Trabalhar sem ter clareza da finalidade conduz à alienação e, por conseguinte, da grupalidade à serialidade, comprometendo desta forma, os indicadores grupais de afiliação e pertença. Uma vez que a pertença também é um indicador de compromisso, à medida que as relações se intensificam, aumenta o grau de operatividade do grupo, ou seja, a capacidade de alcançar a tarefa proposta.

O desenvolvimento de um trabalho em grupo requer respeito mútuo, tolerância e paciência, sendo que uma acontece em decorrência da outra. No entanto, essas virtudes são difíceis de serem adotadas pelas pessoas uma vez que implicam em tolerar e trabalhar com as diferenças. Para as participantes do grupo focal, a existência de conflitos grupais está diretamente relacionada à dificuldade em elaborar e respeitar essas diferenças. Todavia, os conflitos fazem parte da vida, do processo gerencial e são o núcleo de todo grupo. O problema do conflito não é a sua presença, mas a não-resolução, o escamoteamento. No momento que as pessoas aprendem a lidar com as suas diferenças, o conflito, em vez de tornar-se destrutivo, pode ser construtivo e mediador de relações mais efetivas.

Apesar de a Enfermagem constituir-se em uma profissão em que se trabalha geralmente com grupos de profissionais, na maioria das vezes, o graduando não está preparado para encarar o mercado de trabalho sob essa perspectiva. O referencial pichoniano enfatiza a necessidade constante de aprender a aprender, no entanto, o que se percebe no cotidiano do trabalho é que o profissional busca essa aprendizagem na prática, entre erros e acertos, sem fundamentar-se em um aporte teórico adequado. Surge daí os principais impasses na vida profissional - referentes ao relacionamento humano e suas complexidades.

O conhecimento e preparo teórico sobre o tema podem melhor viabilizar o estabelecimento de estratégias para a construção de um trabalho em grupo. Isto possibilitaria aos futuros trabalhadores em saúde, já na sua formação acadêmica, desencadear um processo reflexivo de compreensão dos fenômenos principais existentes no campo grupal, com o objetivo de instrumentalizá-los para o trabalho com e em grupo.

Uma limitação do estudo consistiu na impossibilidade de consolidação do grupo focal com a participação de enfermeiros e auxiliares de enfermagem - proposto inicialmente. A participação conjunta de enfermeiros e auxiliares de enfermagem no grupo focal poderia fornecer um panorama mais amplo acerca do processo grupal.

Com os resultados desta pesquisa, busca-se colaborar na discussão e reflexão acerca do processo grupal nas equipes de enfermagem, trazendo à tona questões referentes ao trabalho das equipes, comunicação e vínculo. Entende-se que o conhecimento sobre processo grupal necessita ser compartilhado, divulgado e discutido desde o ensino formal na graduação e mantido ao longo de toda a carreira profissional uma vez que, já ao concluir a graduação, o profissional parte para o mercado de trabalho, e este, por sua vez, deseja um profissional habilitado. Existe a necessidade de profundos investimentos na construção de competências para coordenar grupos.

À medida que se conhece e se consegue identificar os principais indicadores presentes no processo grupal, pode-se estar dando o primeiro passo em direção à elaboração das ansiedades básicas e modificando a si mesmo na relação que se estabelece com o(s) outro(s). Deste modo, mediante um processo de autoconhecimento, lançando mão de recursos como grupos vivenciais e apoio terapêutico, quando necessário, a equipe pode se conduzir operativamente, considerando não apenas resultados, mas, principalmente, o caminho percorrido até o alcance da tarefa visando a aprendizagem grupal. 


\section{REFERÊNCIAS}

1. Lane STM. O processo grupal. In: Lane SMT, Codo W, organizadores. Psicologia social: o homem em movimento. 13a ed. São Paulo: Brasiliense; 2001. p. 78-98.

2. Dall'Agnol CM, Martini AC. Reuniões de trabalho: mais que uma ferramenta educativa, um processo educativo. Texto Contexto Enferm. 2003;12(1):89-96.

3. Munari DB, Fernandes CNS. Coordenar grupos: reflexão à luz das diretrizes curriculares nacionais do Curso de Graduação em Enfermagem. Rev Gaúcha Enferm. 2004;25(1):26-32.

4. Matumoto S, Fortuna SM, Mishima SM, Pereira MJB, Domingos NAM. Supervisão de equipes no Programa de Saúde da Família: reflexões acerca do desafio da produção de cuidados. Interface Comun Saúde Educ. 2005;9(16):9-14.

5. Grando MK. Reuniões de equipe na Estratégia Saúde da Família a partir do referencial pichoniano de grupo operativo [dissertação]. Porto Alegre: Escola de Enfermagem, Universidade Federal do Rio Grande do Sul; 2007.

6. Pichon-Rivière, E. O processo grupal. 7ạ ed. São Paulo: Martins Fontes; 2005.

7. Pichon-Rivière E, Quiroga AP. Psicologia da vida cotidiana. São Paulo: Martins Fontes; 1998.

8. Brasil. Ministério da Educação. Conselho Nacional de Educação. Resolução CNE/CES n. 3, de 07 de novembro de 2001. Dispõe sobre as diretrizes curriculares nacionais do curso de Graduação em Enfermagem [Internet]. Brasília; 2001 [citado 2009 jul. 18]. Disponível em: http://portal.mec.gov.br/cne/ arquivos/pdf/CESO3.pdf

9. Thiollent M. Metodologia da pesquisa-ação. 9a ed. São Paulo: Cortez; 1998.

10. Hospital de Clínicas de Porto Alegre. Relatório de atividades [Internet]. Porto Alegre: Gráfica do HC Porto Alegre; 2008 [citado 2009 jul. 18]. Disponível em: http://www.hcpa.ufrgs. br/downloads/Publicacoes/relatorio2008.pdf
11. Conselho Nacional de Saúde. Resolução n. 196, de 10 de outubro de 1996. Dispõe sobre as diretrizes e normas regulamentadoras de pesquisas envolvendo seres humanos. Bioética. 1996;4(2 Supl):15-25.

12. Minayo MCS. O desafio do conhecimento: pesquisa qualitativa em saúde. 9ạ ed. São Paulo: Hucitec; 2007.

13. Weirich CF, Munari DB, Bezerra ALQ. Endomarketing: ensaio sobre possibilidades de inovação na gestão em enfermagem. Rev Bras Enferm. 2004;57(6):754-7.

14. Gayotto MLC, Domingues I. Liderança: aprenda a mudar em grupo. 3a ed. Petrópolis: Vozes; 1995. Técnica de grupo operativo: instrumento de intervenção grupal; p. 29-34.

15. Stefanelli MC, Carvalho EC, Arantes EC. A comunicação nos diferentes contextos da enfermagem. Barueri: Manole; 2005.

16. Braga EM, Silva MJP. Comunicação competente: visão de enfermeiros especialistas em comunicação. Acta Paul Enferm [Internet]. 2007 [citado 2009 maio 29];20(4):410-4. Disponível em: http://www.scielo.br/pdf/ape/v20n4/03.pdf

17. Canoletti B. Trabalho em equipe de saúde e de enfermagem: análise sistemática da literatura [dissertação]. São Paulo: Escola de Enfermagem, Universidade de São Paulo; 2008.

18. Bleger J. Temas de psicologia. São Paulo: Martins Fontes; 1991.

19. Maffacciolli R. Os grupos na atenção básica de saúde de Porto Alegre: usos e modos de intervenção terapêutica [dissertação]. Porto Alegre: Escola de Enfermagem, Universidade Federal do Rio Grande do Sul; 2006.

20. Zimermam DE. Como trabalhamos com grupos. Porto Alegre: Artes Médicas; 1997.

21. Pirolo SM, Chaves EC. A equipe de enfermagem e o mito do trabalho em grupo. Rev Esc Enferm USP. 2002;36(4):351-7. 